Available online at https://jurnal.stmikroyal.ac.id/index.php/jurdimas

\title{
PEMBUATAN APLIKASI PENGENALAN RAMBU LAMPU LALULINTAS PADA POLSEK PORSEA
}

\author{
Nuriadi Manurung $^{1 *}$, Mhd. Ihsan ${ }^{2}$, Bachtiar Efendi ${ }^{1}$ \\ ${ }^{1}$ Sistem Komputer, Stmik Royal Kisaran \\ ${ }^{2}$ Sistem Informasi, Stmik royal Kisaran \\ email:*nuriadi0211@gmail.com
}

\begin{abstract}
Traffic signs that are installed on either side of the road that we often see when driving on the highway have certain meanings and goals. The installation of traffic signs is one of the public services that the government must carry out by the relevant agencies for the convenience of road users and reduce the number of traffic accidents. Aside from being a guide, the signs also functioned as a warning for road users about the conditions and situation of the road to be passed. For this reason, road users must understand and understand the meaning of the signs installed. But for various reasons, many people have not had the opportunity to learn and understand the meaning and purpose of signs of traffic signs. With the development of computer technology and video animation, learning methods about understanding the meaning and purpose of traffic signs can be made easier and more efficient to attract the public's interest in understanding them. Because it takes the form of animated videos and tutorials, so it's easy to display and play back if the learning participants don't understand. With the community service from STMIK Royal to Porsea Sector Police, we are trying to help the police station to introduce traffic signs to the community using the animated video tutorial method. This animated video tutorial uses Adobe Flash.
\end{abstract}

Keywords: Adobe Flash, Animation, Traffic Signs

\begin{abstract}
Abstrak: Rambu-rambu lalu lintas yang dipasang pada kanan kiri jalan yang sering kita lihat saat berkendara dijalan raya memiliki arti dan tujuan tertentu. Pemasangan rambu-rambu lalulintas adalah salah satu dari pelayanan publik yang wajib diadakan pemerintah oleh dinas terkait demi kenyamanan pengguna jalan dan mengurangi angka kecelakaan lalulintas. Selain sebagai penunjuk jalan, rambu tersebut juga difungsikan untuk peringatan untuk pengguna jalan tentang kondisi dan situasi jalan yang akan dilalui. Untuk hal tersebut maka pengguna jalan harus mengerti dan memahami arti dari rambu-rambu yang terpasang. Namun dengan berbagai sebab, banyak masyarakat yang belum berkesempatan belajar dan memahami tentang arti dan maksud dari tanda rambu lalu lintas. Dengan berkembangnya teknologi komputer dan video animasi, metode pembelajran tentang pemahaman arti dan maksud dari rambu lalulintas dapat dibuat semakin mudah dan efisien untuk menarik minat masyarakat dalam memahaminya. Karena berbentuk video animasi dan tutorial, sehingga mudah ditampilkan dan putar ulang jika peserta pemebelajaran belum paham. Dengan adanya pengabdian masyarakat dari STMIK Royal ke Polsek Porsea ini, kami berusaha membantu polsek untuk mengenalkan rambu lalulintas kepada masyarakat dengan metode video tutorial animasi. Video tutorial animasi ini menggunakan adobe flash.
\end{abstract}

Kata kunci: Adobe Flash, Animasi, Rambu-Rambu Lalulintas 
Available online at https://jurnal.stmikroyal.ac.id/index.php/jurdimas

\section{PENDAHULUAN}

Seiring pertumbuhan penduduk, peningkatan kendaraan di jalan raya pun cukup signifikan sehingga jalan raya semakin padat yang sehingga berpotensi banyaknya pelanggaran lau lintas yang terjadi. Salah satu factor yang mempengaruhi sehingga banyaknya pelanggaran tersebut karena kurangnya kesadaran masyarakat dan pengetahuan tentang bahaya pelanggaran lalu lintas. Berbagai pelanggaran lalu lintas sangat sering kita lihat di berbagai tempat, bukan hanya terjadi di pemberhentian lampu merah saja. Bisa saja terjadi di trotoar, zebracros dan bahkan kesalahan tersebut dilakukan bukan di sengaja. UU No 22 Tahun 2009 tentang Lalu Lintas dan Angkutan Jalan (UULLAJ). Undangundang baru ini mengatur lebih tegas tentang jalan raya. Kemunculan undangundang baru ini tentu saja menerbitkan sebuah harapan terciptanya lalu lintas yang tertib dan ramah bagi para pengguna jalan. Pada kehidupan keseharian, tidak banyak yang mengetahui tentang ganjaran bagi para pelanggar aturan, dan ini sering dimanfaatkan oknum petugas untuk berdamai dengan membayar sejumlah uang Birukut berbagai pelanggaran yang tanpa kita sadari sering kita lakukan dan akibatnya sangat fatal.

UU No 22 Tahun 2009 tentang Lalu Lintas dan Angkutan Jalan (UU LLAJ). Undang-undang baru ini mengatur lebih tegas tentang jalan raya. Kemunculan undang-undang baru ini tentu saja menerbitkan sebuah harapan terciptanya lalu lintas yang tertib dan ramah bagi para pengguna jalan. Pada kehidupan keseharian, tidak banyak yang mengetahui tentang ganjaran bagi para pelanggar aturan.
Dalam hal ini sebenarnya peraturan-peraturan tersebut sudah diterapkan oleh pihak kepolisian kita, tetapimasih banyak pengendara kendaaan bermotor yang tidak mentaati peraturanpraturan yang telah berlaku di jalan raya, sehingga menyebabkan banyak terjadinya kecelakan-kecelakaan lalulintas ataupun terjadi kemacetan-kemacetan yang ditimbulkan oleh para pengguna jalan raya yang tidak mau patuh terhadap peraturan-peraturan rambu-rambu lalu lintas yang telah berlaku di Indonesia khususnya di porsea.

\section{METODE}

Tahapan atau langkah-langkah yang ditempuh agar terlaksana dengan baik dan lancar serta tercapainya tujuan kegiatan pengabdian kepada masyarakat ini adalah:

1. Mempersiapkan materi yang akan diberikan, baik modul, slide presentasi, dan alat peraga lainnya.

2. Memastikan tempat dan fasilitas pendukung seperti infocus, projector, dan lain-lain sudah standby pada saat kegiatan akan dilangsungkan.

3. Sebelum kegiatan dilakukan peserta yang mengikuti kegiatan ini harus sudah memiliki komputer atau laptop sebagai alat praktek.

4. Menjelaskan teori tentang materi aplikasi yang digunakan.

5. Paktek langsung pada komputer atau laptop dalam mengimplementasikan animasi.

6. Membahas kasus yang berkaitan dengan rambu lampu lalulintas dan animasi.

7. Diskusi dan tanya jawab.

8. Dalam kegiatan ini kapolsek menyediakan tempat selama kegiatan dilang- 
Available online at https://jurnal.stmikroyal.ac.id/index.php/jurdimas

sungkan dan fasilitas-fasilas penunjang yang mereka punya untuk mendukung kegiatan ini berjalan dengan baik dan lancar.

Setelah kegiatan pengabdian kepada masyarakat ini dilakukan, maka langkah selanjutnya adalah Tim pengabdian kepada masyarakat melakukan monitoring selama 1 sampai 2 kali pada daerah kota porsea untuk melihat masyarakat dalam mematuhi rambu lalulintas.

\section{PEMBAHASAN}

a. Multimedia

Multimedia adalah merupakan gabungan dari dua kata media dan multi. Media merupakan satu bentuk interaksi manusia yang sesuai dengan kebutuhan dan pemrosesan menggunakan komputer seperti video, audio, teks, grafik, animasi. Sedangkan multi merupakan gabungan beberapa media tersebut yang diintegrasikan dalam sistem atau aplikasi yang sama" (Vaughan, 2008)

b. Animasi

Animasi adalah gambar begerak berbentuk dari sekumpulan objek (gambar) yang disusun secara beraturan mengikuti alur pergerakan yang telah ditentukan pada setiap pertambahan hitungan waktu yang terjadi. Gambar atau objek yang dimaksud dalam definisi di atas bisa berupa gambar manusia, hewan, maupun tulisan. Pada proses pembuatannya sang pembuat animasi atau yang lebih dikenal dengan animator harus menggunakan logika berfikir untuk menentukan alur gerak suatu objek dari keadaan awal hingga keadaan akhir objek tersebut. Perencanaan yang matang dalam perumusan alur gerak berdasarkan logika yang tepat akan menghasilkan animasi yang menarik untuk disaksikan. c. Jenis-Jenis Animasi

Animasi frame animasi cel Merupakan lembaran-lembaran yang membentuk animasi tunggal

Menggunakan materi celluloid Digambar manual (dengan tangan)

\section{d. Animasi Frame}

Rangkaian gambar statis yang terletak dalam beberapa frame berurutan, apabila frame-frame tersebut dijalankan akan menghasilkan ilusi pergerakan obyek.

e. Pengertian Adobe Flash

Adobe Flash adalah software multimedia unggulan dan populer untuk menambahkan animasi dan interaktif website" (Andi Sunyoto, 2005: iii). Flash tidak hanya digunakan untuk aplikasi $w e b$, tetapi dapat dikembangkan untuk membangun aplikasi desktop karena aplikasi Flash selain dikompilasi menjadi format .swf, Flash juga dapat dikompilasi menjadi format .exe. Flash menggunakan bahasa pemrograman bernama $A c$ tionScript. Flash lahir dari kepala seseorang bernama Jonathan Gay. Jon yang gemar menulis game dan membuat animasi di komputer. Ia menciptakan game Mac Airborne! tahun 1985, ketika ia masih duduk di bangku sekolah.

Tahun 1993 ia mendirikan FutureWave Software dengan produk pertama SmartSketch. Inilah cikal bakal Macromedia Flash. Tahun 1995 SmartSketch berganti nama menjadi CelAnimator. Menjelang akhir 1995, $\mathrm{Fu}$ tureWave sempat mengalami masalah finansial dan mencari pembeli. Tiga calon yang ketika itu didekatinya adalah John Warnock dari Apple, lalu juga Adobe dan Fractal Designs.

Di bulan Juli 1996, CelAnimator berubah nama kembali menjadi FutureSplash Animator. Produk ini menimbulkan minat di kalangan industri. Tak 
Available online at https://jurnal.stmikroyal.ac.id/index.php/jurdimas

kurang dari Microsoft yang menggunakan dan amat menyukainya. Disney juga sama. Ketika itu MSN ingin dibuat mengikuti model televisi, dan animasi-animasi full screen dibuat dengan FutureSplash.

f. Langkah-langkah membuat rambu lampu lalulintas.

1. Menjalankan Program Adobe Flash Langkah untuk menjalankan Adobe Flash Profesional CS3, klik start > All program $>$ Adobe $>$ Adobe Flash.

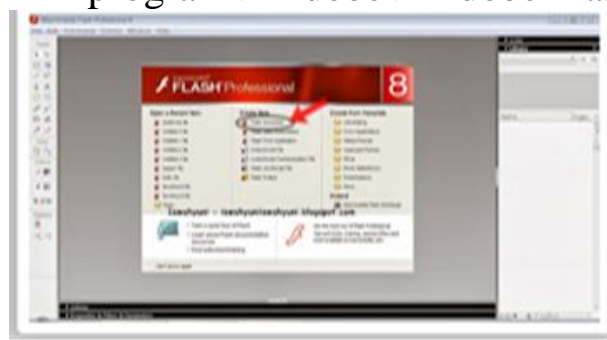

Gambar 1. Adobe Adobe Flash.

2. Pada menu Insert, pilih New Symbol (crtl $+\mathrm{F} 8)$.

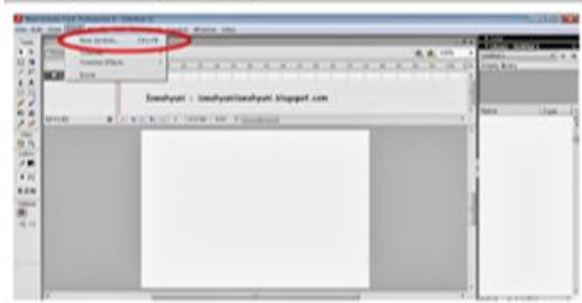

Gambar 2. Lembar Kerja Baru

3. Buat nama symbol menjadi roda, Type :Movie Klip a Ok.

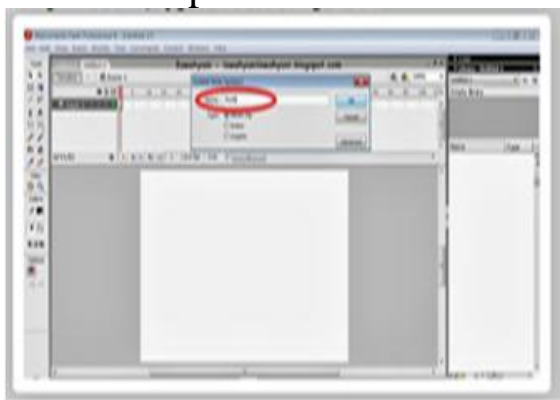

Gambar 3. Movie Klip a

4. Gambarlah roda seperti pada gambar dibawa ini.

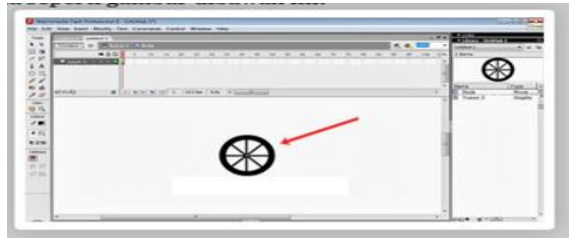

Gambar 4. Roda

5. buatlah gambar mobil denganmenggunakan "line tool atau rectangle tool langkah ini bias andakreasikan sesuai selerah masing-masing karena cukup menggabung-gabungkan garis hingga menyerupai bentuk mobil yang diingginkan. Kemudian klik kanan pada gambar mobil tersebut dan klik selesc all, klik kanan klik" convert to symbol" pilih "movie clip" dang anti nama "symbol 1 menjadi bodymobil kemudian klik. ok gambar bodi mobil yang sudah di desain.

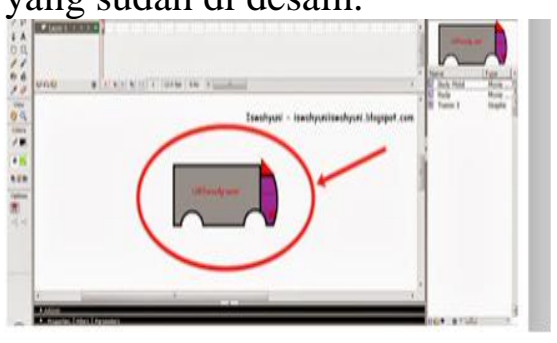

Gambar 5. Mobil

6. langkah selanjutnya yaitu membuat agar mobil beserta ban tersebut terlihat berjalan kea rah kanan. Pertama: kelik pada symbol body mobil kemudian pada frame 5 klik insert keyframe lalu pindah ke posisi ke atas.

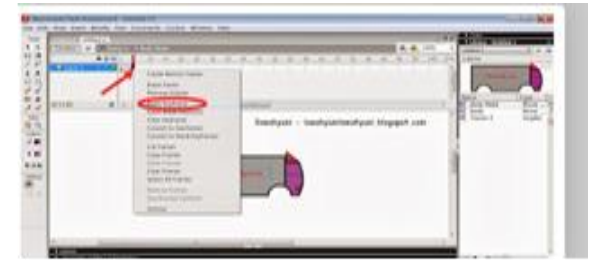

Gambar 6. Proses penyatuan ban ke body mobil

7. masukan symbol roda dan simbol body mobil kedalam scene 1 satukan 
Available online at https://jurnal.stmikroyal.ac.id/index.php/jurdimas

ban dan body mobil yang telah didesain seperti pada gambar dibawa ini.

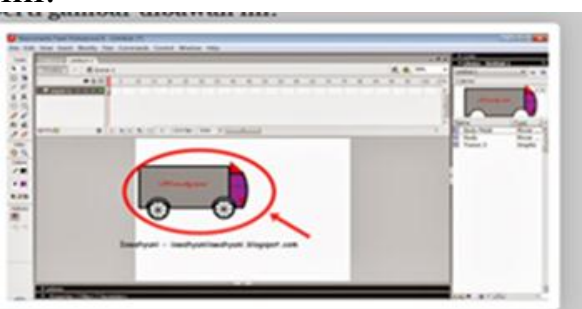

Gambar 7. ban yang telah di satukan dengan body mobil

8. buatlah gambar lampu lalu lintas dengan menggunakan Oval Tool, Line Tool atau rectangle tool langkah ini bias anda kreasikan sesuai selera masing-masing karena cukup menggabung-gabungkan garis hingga menyeruapai bentuk lampu lalu lintas yang diinginkan.

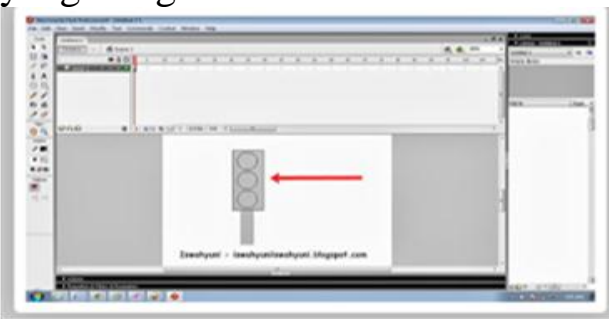

Gambar. 8. Gambar lampu lalulintas

9. pada frame 1 buatlah lampu lalu lintas berwarna merah, kedua warna (kuning \& hijau )tidak usah dikasi warna, seperti gambar dibawa ini.

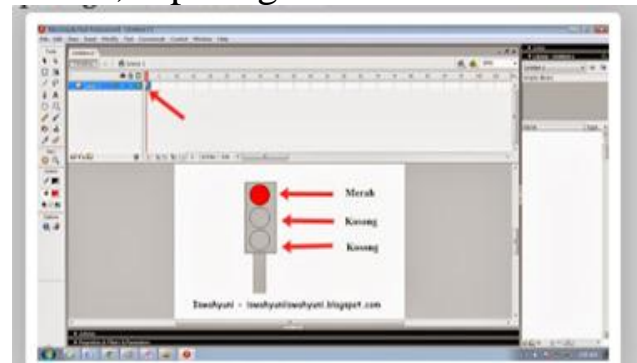

Gambar 9. Lampu lalu lintas berwarna merah

10. buatlah lampu lalu lintas berwarna kuning kedua warna (merah \& hijau )tidak usah dikasi warna, seperti gambar dibawa ini.

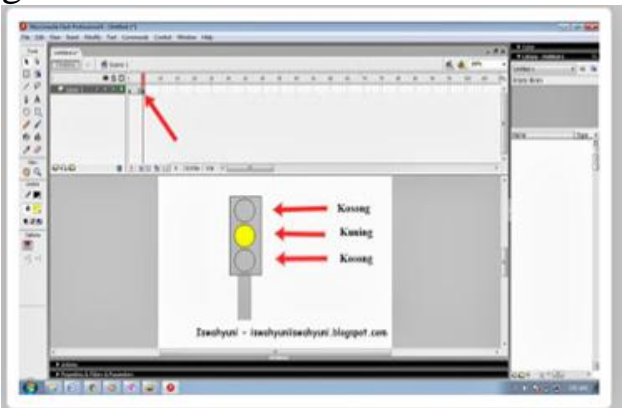

Gambar 10. Lampu lalu lintas berwarna kuning

11. buatlah lampu lalu lintas berwarna hijau kedua warna (merah \& Kuning )tidak usah dikasi warna, seperti gambar dibawa ini.

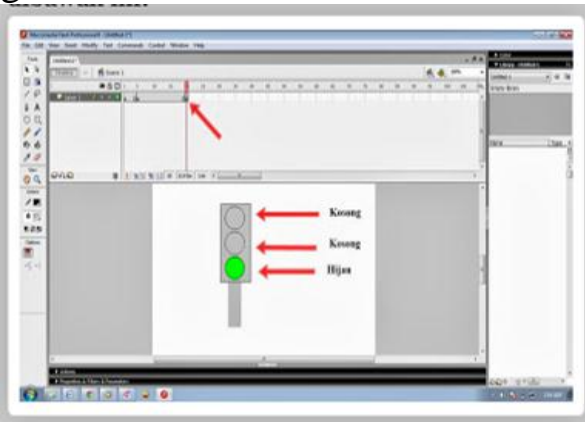

Gambar 11. Lampu lalu lintas berwarna hijau

12. gambar atau desain membuat animasi mobil berjalan dan lampu merah.

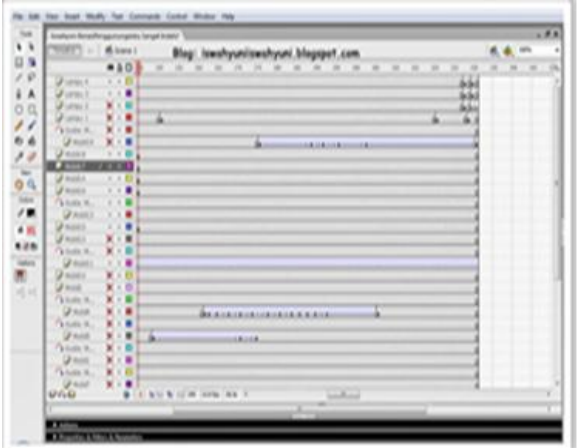

Gambar 12. desain membuat animasi mobil berjalan dan lampu merah. 13. Motion Tween \& Symbol. 
Available online at https://jurnal.stmikroyal.ac.id/index.php/jurdimas

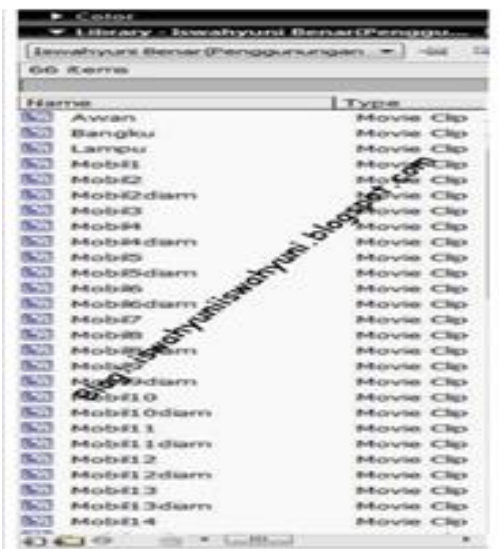

\section{Gambar 13. Motion Tween \& Simbol}

14. Design.

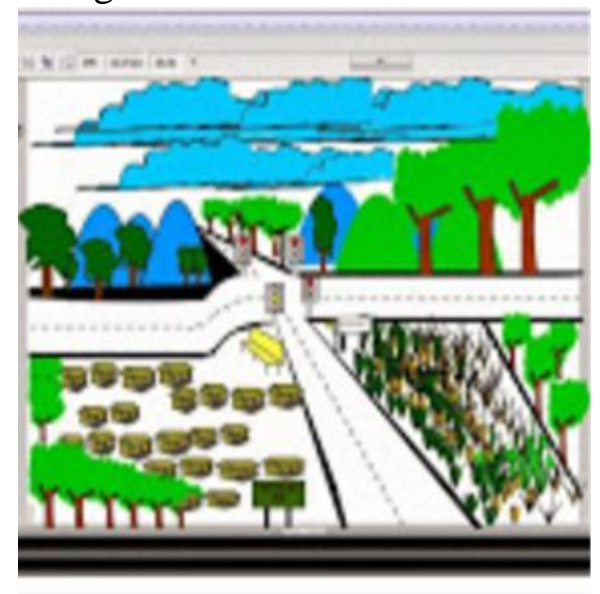

15. Hasil keseluruhan.

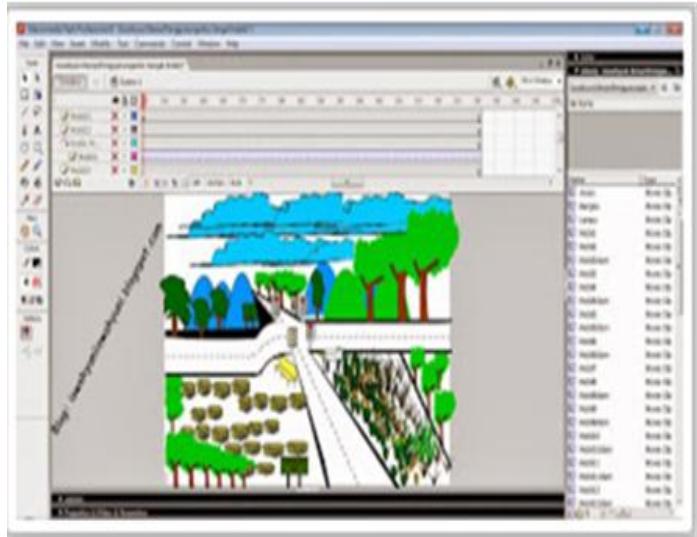

Gambar 13. Motion Tween \& Simbol

\section{SIMPULAN}

Kesimpulan dari Kegiatan Pengabdian Masyarakat ini adalah :

1. Dapat memberikan manfaat untuk pegawai di Polsek Porsea dalam hal mensosialisasikan rambu rambu lalu lintas.

2. Para Pegawai Polsek Porsea dapat memahai cara membuat animasi rambu lalu lintas berbasis multimedia. Sehingga dapat diimplementasikan nantinya.

3. Dengan adanya aplikasi rambu lalu lintas berbasis multimedia pada Polsek Porsea ini dapat memudahkan masyarakat pada umumnya dalam hal informasi masalah rambu lalu lintas pada Polsek Porsea.

\section{DAFTAR PUSTAKA}

Jurnal Serambi Engineering, Volume I, Nomor 1, Agustus 2016.

Journal of Animation and Games Studies, Vol.3 No.1 - April 2017

Sunyoto, A. (2005). Konsep sistem informasi. Jakarta: Deepublish. 